\title{
UN EXPONENTE DE LA PROBLEMATICA ACTUAL ENTRE COMUNIDADES AUTONOMAS Y PROVINCIAS: LA GESTION ORDINARIA DE LOS SERVICIOS PERIFERICOS PROPIOS DE LA COMUNIDAD AUTONOMA A TRAVES DE LAS DIPUTACIONES PROVINCIALES
}

por

\author{
Antonio Calonge Velázquez \\ Profesor Titular de Derecho Administrativo de la Universidad \\ de Valladolid
}

SUMARIO: I. INTRODUCCION.-II. LAS TECNICAS DE RELACION ENTRE LA COMUNIDAD AUTONOMA Y LAS DIPUTACIONES PROVINCIALES.-III. ANALISIS ESPECIAL DE LA GESTION ORDINARIA DE LOS SERVICIOS PERIFERICOS PROPIOS DE LA COMUNIDAD AUTONOMA A TRAVES DE LAS DIPUTACIONES PROVINCIALES. - IV. UN EJEMPLO: EL CASO ANDALUZ.-V. REFLEXION CRITICA.

\section{INTRODUCCION}

A estas alturas de funcionamiento del llamado por muchos «Estado de las Autonomías» es claro que una de las dificultades y problemas mayores de resolver que se nos han presentado es el de la articulación entre las distintas Administraciones Públicas - un tema clásico del Derecho administrativo- $\mathrm{y}$, más concretamente, el de las relaciones entre las Comunidades Autónomas y las Diputaciones 
Provinciales, el de las relaciones entre la Administración autonómica y la Administración provincial. Es éste un problema de plena actualidad y fundamentalmente práctico (no es ni más ni menos que el problema de la organización territorial de la Comunidad Autónoma y el reparto de poderes), un tema que ha suscitado y suscita debates y preocupaciones. La doctrina científica especializada y la realidad práctica se están ocupando de este problema (1).

Este tema no es en absoluto nuevo para nosotros. Como ha escrito el profesor CLAVERo ARÉVALO, "siempre que se ha aprobado una Constitución federal o de autonomías regionales el tema de la Provincia ha quedado en entredicho» (2). Así, el Proyecto de Constitución federal de 1873, en su artículo 100, otorgaba a los Estados la competencia para establecer libremente su propia organización territorial. En su misma Exposición de Motivos plantea los problemas que presenta la división territorial, y concluye diciendo: «... señalamos como nuevos Estados de la República los antiguos Reinos de la Monarquía, y dejamos que los Estados conserven, si quieren, las Provincias, o regulen a su arbitrio la más conveniente y sabia división territorial. De esta suerte llegamos a un arreglo prudentísimo en la cuestión que se halla quizá más erizada de dificultades y peligrosa». Y durante la Segunda República, concretamente el Estatuto catalán de 1932, en su artículo 10, atribuía competencia exclusiva a la Generalitat sobre el Régimen local y la división territorial, no reconociendo más Ente local obligatorio que el Municipio, y señalaba más adelante que «... para el cumplimiento de sus

(1) Son numerosos los trabajos que sobre esta cuestión se han publicado en los últimos años. Vid. a modo de ejemplo: MoRell Ocaña, Luis: «La Provincia en la configuración y ordenación territorial de las Comunidades Autónomas», REDA, número 31, octubre-diciembre 1981, págs. 613 y sigs.; MARTín MATEO, Ramón: "La concertación competencial de Comunidades Autónomas y Diputaciones Provinciales», $R E D A$, núm. 36, enero-marzo 1983, págs. 5 y sigs.; EmBID IrUjo, Antonio: "Las relaciones de las Comunidades Autónomas con las Diputaciones Provinciales», RevisTA DE Estudios DE LA VIDA LOCAL, núm. 220, octubre-diciembre 1983, págs. 493 y sigs.; ANGlaDA Gotor, Santiago: «Junta de Andalucía y Diputaciones Provinciales: Articulación de servicios periféricos», REvisTa de Estudios DE LA VIDA LOCAL, número 221, enero-marzo 1984, págs. 47 y sigs. Aparte del vol. II del libro de Santiago MuÑoz MACHADO: Derecho Público de las Comunidades Autónomas, Civitas, Madrid, 1984, págs. 131 y sigs., y los volúmenes de Organización territorial del Estado (Comunidades Autónomas y Administración Local), de la Dirección General de lo Contencioso del Estado, IEF, Madrid, 1984 y 1985, respectivamente.

La realidad práctica nos la están demostrando los distintos medios de comunicación social que reiteradamente se hacen eco de las distintas posiciones partidistas que sobre el particular existen.

(2) Clavero Arévalo, Manuel: "La Provincia ante una encrucijada histórica en el ciento cincuenta aniversario de su creación (1833-1983)", Revista de Administración Pública, núms. 100-102, vol. III, enero-diciembre 1983, pág. 2131. 
UN EXPONENTE DE LA PROBLEMATICA ACTUAL ENTRE COMUNIDADES AUTONOMAS... 705

fines la Generalitat podrá establecer las demarcaciones territoriales que estime más convenientes», teniendo como resultados prácticos la creación y constitución de las Comarcas, desechándose de este modo la idea de la Provincia. La nueva organización territorial del Estado surgida de la Constitución de 29 de diciembre de 1978 ha vuelto a poner sobre el tapete $\tan$ arduo $y$, a la vez, tan interesante problema.

La cuestión surge, en definitiva, cada vez que se ha creado un nuevo Ente territorial intermedio, ya sea Estado-miembro, Región o Comunidad Autónoma, entre los Entes locales y el Estado. El enfrentamiento Región-Provincia, si así queremos llamarlo, viene, pues, de lejos, no aparece ahora, en contra de lo que algunos piensan, en nuestro presente constitucional.

Ha estado en el pensamiento administrativo clásico que la existencia de la Región supone la desaparición de la Provincia, y viceversa. Hoy podemos afirmar que nada más lejos de la realidad. Como han puesto de manifiesto muchos de los autores, ambas se necesi$\tan$ y se complementan en su existencia, "han de ser una pieza básica de las Comunidades pluriprovinciales, pues los sentimientos provincialistas están muy vivos en la mayor parte de la población» (3). No olvidemos que las Provincias han sido, como ha escrito el profesor GuAIta MARTORELL, «el motor y rampa de lanzamiento de las Comunidades Autónomas» (4), «el elemento básico y fundacional de las Comunidades Autónomas» (5) y que incluso los mismos Estatutos de Autonomía las han reconocido este carácter e importancia; así, por ejemplo, nuestra norma institucional básica, el Estatuto de Autonomía de Castilla y León, aprobado por la Ley Orgánica 4/1983, de 25 de febrero ( $B O E$ de 2 de marzo), lo ha reconocido en sus artículos $1 .^{\circ}, 1 ; 2 .^{\circ} ; 10,2$, y 19, 2 . Además, nuestra Norma fundamental, como es de todos sabido, ha constitucionalizado a las Provincias o, lo que es lo mismo, las ha configurado como Entidades necesarias o de existencia obligatoria (arts. 137 y 141 de la Constitución) (6), las ha reforzado con un gran formalismo: la

(3) Informe de la Comisión de Expertos sobre Autonomias, CEC, Madrid, 1981, página 27.

(4) Guaita Martorell, Aurelio: «Las Provincias españolas a partir de la Constitución de 1978», Revista de Administración Pública, núm. 94, enero-abril 1981, página 37.

(5) Guaita Martorell, Aurelio: «Perspectiva de la Administración local desde los Estatutos de Autonomía. Castilla-La Mancha», Revista dE Estudios DE LA VIDA LOCAL, núm. 224, octubre-diciembre 1984, pág. 814.

(6) Entrena Cuesta, Rafael: *La Administración local en la Constitución de 1978», en La Administración en la Constitución, CEC, Madrid, 1981, págs. 111-117. 
alteración de los límites provinciales sólo es posible mediante Ley Orgánica (art. 141, 1), y, por último, las ha dotado de autonomía, si bien diferente de la de «Nacionalidades y Regiones» (7), para la gestión de sus respectivos intereses, como señala expresamente el artículo 137 de nuestro Texto constitucional. En definitiva, podemos decir con el profesor Clavero (8) que nuestra Constitución, a pesar de reconocer el derecho al autogobierno de las Nacionalidades y Regiones, es provincialista.

Pues bien: sentadas estas bases, vamos a pasar al núcleo del trabajo, que no es otro que el análisis y estudio de las técnicas de articulación, configuradas por nuestro Ordenamiento jurídico, entre ambos Entes territoriales: Comunidad Autónoma y Provincia, y, más concretamente, de una sola de las establecidas por nuestra vigente legislación y que sirve de título al presente trabajo.

\section{LAS TECNICAS DE RELACION ENTRE LA COMUNIDAD AUTONOMA Y LAS DIPUTACIONES PROVINCIALES}

Arrancando este estudio desde la aprobación de la Constitución en diciembre de 1978, lo primero que hemos de hacer notar es la ausencia en esta Norma fundamental de cualquier referencia directa al tema objeto de estudio. "Los Entes locales y las Comunidades Autónomas - ha observado acertadamente el profesor ENTRENA CUESTA - se ignoran mutuamente en el Texto constitucional, que prescinde de establecer cualquier tipo de relación entre las dos categorías» (9). Aunque sí existen diversos condicionantes o referencias indirectas al tema, como, por ejemplo, la constitucionalización de los principios de descentralización, desconcentración y coordinación conforme a los cuales debe actuar toda Administración Pública $($ art. 103,1$)(10)$ o la atribución de autonomía a la Provincia para la gestión de sus respectivos intereses, como ya antes hemos señalado. No obstante, pienso que aunque no fuera éste el texto legislativo más idóneo para regular las relaciones entre ambas Admi-

(7) Sobre esta distinción vid. MARTf́NEz LOPEZ-MuÑIz, José-Luis: «Provincia-Entidad local y Comunidades Autónomas uniprovinciales», REvisTA DE EsTUdios DE LA VIDA LOCAL, núm. 209, enero-marzo 1981, págs. 65 y sigs.

(8) Clavero Arévalo, M.: «La Provincia...", cit., pág. 2135.

(9) Entrena Cuesta, R.: «La Administración local...», cit., pág. 105.

(10) En contra de esta tesis vid. MeILÁN GIL, José-Luis: «La articulación de los ordenamientos local y autonómico», REDA, núm. 44, octubre-diciembre 1984, páginas $667-669$. 
nistraciones Públicas, sí que debía, al menos, haberse referido a las mismas y haber establecido sus principios inspiradores.

$\mathrm{Y}$ va a ser el Informe emitido por la Comisión de Expertos sobre Autonomías el primer documento que abordará expresamente el problema planteado, aunque con anterioridad encontremos precedentes en nuestra doctrina y en nuestra legislación (11). Partiendo de que las Provincias «deben sostener el peso principal de la acción pública en el marco de cada Comunidad Autónoma»(12), la citada Comisión ofrecerá soluciones indicando distintas técnicas de relación entre la Administración autonómica y la Administración provincial.

El grupo de expertos acomete este problema bajo la idea principal de la participación de las Diputaciones Provinciales en la acción administrativa regional (13), aconsejando que los Estatutos de Autonomía y las propias Leyes de las Comunidades Autónomas asignen a las Diputaciones Provinciales competencias propias de la $\mathrm{Co}$ munidad Autónoma (14) o le delegue su ejercicio, siempre bajo la dirección y control de ésta. El mencionado Informe continúa aconsejando, finalmente, por lo que a este tema se refiere, atribuir a las Diputaciones Provinciales la gestión ordinaria, en el territorio de la Provincia, de los servicios propios de la Administración autonómica (15).

Como vemos, son tres las técnicas de relación que diseña y aconseja la denominada "Comisión Enterría»: la atribución de competencias propias de la Comunidad Autónoma a las Diputaciones Provinciales (descentralización o descentralización en régimen de tutela) (16), la delegación de competencias y la realización de la gestión ordinaria de los servicios periféricos de la Comunidad Autó-

(11) Así, puede verse: GARcf́a dE ENTERRfa, Eduardo: "Administración local y Administración periférica del Estado: problemas de articulación", en La Administra ción española, IEP, Madrid, 1961, pág. 159, y MORRLL OCAÑA, L.: «La articulación entre la Administración del Estado y las Entidades locales», en Problemas políticos de la Vida local, Delegación Nacional de Provincias del Movimiento, Madrid, 1972, página 226. Ambos autores hablan de asunción de la gestión de los servicios estatales por las Entidades locales, pero por vía de delegación.

Por lo que hace referencia a la legislación, más adelante nos ocuperemos de ella.

(12) Informe..., cit., pág. 66.

(13) Ibidem, págs. 24-27.

(14) Ibídem, pág. 67.

(15) Ibídem, págs. 26-27.

(16) MARTINEZ LOPEZ-MuÑIz, J. L.: «Provincias y Comunidades Autónomas pluriprovinciales: problemas de articulación», en Organización territorial..., vol. III, citado, pág. 2042. 
noma por parte de los órganos de gobierno y administración de las Provincias, esto es, las Diputaciones Provinciales.

Estas soluciones presentadas por la Comisión de Expertos se vieron primeramente reflejadas en los Acuerdos o Pactos autonómicos de julio de 1981. Así, el punto decimosexto de los mencionados Acuerdos es del siguiente tenor:

aEn la redacción de los Estatutos de las Comunidades pluriprovinciales ha de preverse que las Diputaciones Provinciales gestionen ordinariamente los servicios confiados a aquéllas bajo su dirección y control, así como que puedan recibir competencias por transferencia o delegación» (17).

Estos Acuerdos, escrupulosamente respetados y cumplidos por los dos grandes partidos políticos firmantes de los mismos (UCD y PSOE), tuvieron su primer reflejo jurídico-positivo en la famosa y polémica Ley Orgánica y de Armonización del Proceso Autonómico, comúnmente denominada LOAPA, que en su artículo 11,1 , señalaba lo siguiente:

«Sin perjuicio de las competencias que la legislación de Régimen local, tanto del Estado como de las Comunidades Autónomas, atribuya a las Diputaciones Provinciales, las leyes de las Comunidades Autónomas podrán transferir las competencias propias a las Diputaciones o delegarlas su ejercicio siempre bajo la dirección y control de éstas. Las Diputaciones Provinciales podrán asumir la gestión ordinaria de los servicios propios de la Administración autónoma en el territorio de la Provincia, en los términos que los Estatutos y dichas leyes establezcan...".

Esta Ley, como es de todos conocido, fue, en su mayor parte, declarada inconstitucional por el Alto Tribunal en su Sentencia 76/ 1983, de 5 de agosto (18), pero no fue así declarada en esta parte referente a las relaciones Comunidad Autónoma-Diputaciones Provinciales; tampoco los recurrentes la impugnaron en su totalidad, sino solamente en los incisos primero y último de este artículo 11, 1 , y no todos.

Posteriormente este texto que acabamos de transcribir pasó a convertirse en el artículo $5 .^{\circ}, 1$, de la Ley 12/1983, de 14 de octubre,

(17) Informe..., cit., pág. 103.

(18) Suplemento al Boletín Oficial del Estado de 18 de agosto de 1983, páginas 29 a 66 . 
UN EXPONENTE DE LA PROBlematica ACTUAL ENTRE COMUNidAdES AUTONOMAS... 709

del Proceso Autonómico ( $B O E$ de 15 de octubre), impropiamente denominada LPA.

La Ley reguladora de las Bases del Régimen local, la Ley 7/1985, de 2 de abril, recientemente ha vuelto a incidir y profundizar sobre este tema al regular en sus artículos $7 .^{\circ}, 8 .^{\circ}, 27,36$ y 37 y en el capítulo II del Título $\mathrm{V}$, que lleva por rúbrica «Relaciones interadministrativas», las técnicas que en su momento diseñó la tantas veces mencionada Comisión de Expertos: transferencia de competencias, delegación de competencias y gestión ordinaria de los servicios periféricos propios de la Comunidad Autónoma, así como coordinación y cooperación.

Por lo que a las Provincias hace referencia, el artículo $8 .^{\circ}$ de esta Ley señala que éstas podrán realizar la gestión ordinaria de los servicios propios de la Administración autonómica, y en los artículos 36 y 37 se establecen, respectivamente, las técnicas de la transferencia y la delegación de competencias.

Pero no solamente en las leyes hasta ahora enunciadas el legislador estatal ha seguido las líneas marcadas por la «Comisión Enterría». Los Estatutos de Autonomía, que son Leyes Orgánicas del Estado, tal y como establecía el Informe, aprobados con posterioridad a los Pactos o Acuerdos autonómicos (prácticamente todos, a excepción de los de las denominadas «Nacionalidades»), también han reproducido en algunos de sus preceptos las técnicas de relación que más arriba hemos señalado (19).

El Estatuto de Autonomía de nuestra Región, el Estatuto de Autonomía de Castilla y León, sirve perfectamente de ejemplo de esto que afirmamos. En su artículo 20, bajo el epígrafe general de «Relaciones con la Comunidad», se describen las técnicas de relación de la Comunidad Autónoma con las Diputaciones Provinciales comprendidas en su ámbito territorial (20). El apartado $2 .^{\circ}$ de dicho precepto estatutario se refiere a la gestión ordinaria de los servicios periféricos propios de la Comunidad Autónoma a través de las Diputaciones Provinciales, y el apartado $4 .^{\circ}$ se refiere a la transferencia o delegación de competencias propias de la Comunidad en las Diputaciones Provinciales y restantes Corporaciones locales.

(19) Así pueden verse los artículos 4 del Estatuto andaluz, 47 del valenciano, 45 del aragonés, 30 del castellano-manchego, 22 del canario, 16 del extremeño, 41 del balear y 20 del castellano-leonés.

(20) Un comentario a este precepto puede verse en Comentarios al Estatuto de Autonomía de la Comunidad Autónoma de Castilla y León, dirigidos por Enrique RIVERO YSERN, Ministerio de Administración Territorial-Instituto de Estudios de Administración Local, Madrid, 1985, págs. 148 y sigs. 
Las técnicas enunciadas en el Informe de la Comisión de Expertos sobre Autonomías las vemos, pues, reflejadas en nuestra «norma institucional básica»: transferencia, delegación y gestión ordinaria de los servicios propios de la Comunidad Autónoma, así como la coordinación, principio de actuación de las Administraciones Públicas, según establece el apartado $10^{\circ}$ del artículo 103 de nuestra Constitución.

\section{ANALISIS ESPECIAL DE LA GESTION ORDINARIA DE LOS SERVICIOS PERIFERICOS PROPIOS DE LA COMUNIDAD AUTONOMA A TRAVES DE LAS DIPUTACIONES PROVINCIALES}

Esta técnica de relación entre Comunidad Autónoma y Diputaciones Provinciales ha tenido su primera expresión actual, como hemos visto, en el Informe que la Comisión de Expertos sobre Autonomías elevó al Gobierno de la Nación en el mes de mayo de 1981, tomándola, como ha señalado el profesor MuÑoz MACHADo (21), del ordenamiento italiano; en particular, del artículo 118, 3, de su Constitución.

Así es; el apartado tercero del artículo 118 de la Constitución italiana de 27 de diciembre de 1947 establece que «la Región ejercerá normalmente sus funciones administrativas delegándolas en las Provincias, en los Municipios o en otras Corporaciones locales, o valiéndose de sus oficinas».

Es evidente, pues, que los miembros de la Comisión de Expertos, primero, y los legisladores, después, se inspiraron en este precepto constitucional para introducir en nuestro Ordenamiento jurídico la técnica de relación interadministrativa que vamos a analizar. En Italia esta técnica se conoce con el nombre de avvalersi o avvalimento.

Las diferencias que existen en este punto entre nuestra Norma fundamental y la italiana son profundas. En primer lugar, porque nuestra Constitución, como hemos dicho al principio, no se ha referido expresamente al tema de las relaciones entre Comunidades Autónomas y Entes locales, mientras que la Constitución italiana sí lo ha hecho. Y, en segundo lugar, porque nuestra Constitución ha sido extremadamente respetuosa con el principio de autogobierno,

(21) Muñoz Machado, S.: Derecho Público..., vol. II, cit., pág. 232. 
no señalando ni siquiera, por lo menos para las Comunidades Autónomas que han accedido a la autonomía por la vía del artículo 143 del Texto constitucional, que son la mayoria, cuáles debieran ser sus principales órganos de gobierno, mientras que la Constitución italiana sí lo ha hecho (en el art. 121 señala que «los organismos de las Regiones serán: el Consejo Regional, la Junta y su Presidente...»), y en el precepto que más arriba hemos transcrito (el 118,3 ) establece incluso un esquema de Administración indirecta de las Regiones al decir que sus funciones administrativas serán ejercidas normalmente por las Provincias, Municipios u otras Corporaciones locales mediante la delegación o valiéndose de sus oficinas.

Sin entrar a fondo en la discusión doctrinal que se ha producido en Italia acerca de estas dos técnicas: la delegazione y l'avvalersi o l'avvalimento, mucho más con respecto a la primera que a la segunda, lo que sí queremos manifestar, por lo que se refiere a la segunda de las técnicas mencionadas (l'utilizzacione degli uffici degli Enti locali), es que esta técnica no ha tenido mucha fortuna ni en la doctrina ni en la práctica (22). En la doctrina ha suscitado muchos recelos, negándose que tal instrumento pueda considerarse como una aplicación del principio de descentralización y de autogobierno (23); antes al contrario, se trata de un instrumento que constituye «un módulo de coordinación vertical de tipo jerárquico» (24), que responde al objetivo de centralizar el ejercicio de ciertas funciones mediante la atracción de los aparatos burocráticos de los Entes menores hacia el Ente regional (25) o, en el mejor de los casos, responde al objetivo de desconcentración (26). Se trata, ha dicho ROVERSI MONACo (27), de una verdadera y propia incardinación de un órgano de un Ente en la estructura organizativa del otro Ente.

(22) Así puede verse en TERESI, Francesco: «La delegazione e l'avvalersi come strumenti di coordinamento tra la Regione ed i minore Enti locali territoriali: aspetti problematici», Il Foro Amministrativo, tomo III, 1971, pág. 364.

(23) Vid., entre otros, RoversI MONACO, Fabio: La delegazione amministrativa nel quadro dell'ordinamento regionale, Giuffrè editore, Milano, 1970, págs. 145 y siguientes, y ORSI BATTAGLINI, Andrea: Le autonomie locali nell'ordinamento regionale, 'Giuffrè editore, Milano, 1974, págs. 330 y sigs.

(24) VANDELLI, Luciano: "Comentario al artículo 118 de la Constitución», en Commentario della Costituzione. Le Regione, le Province $i$ Comuni, Zanichelli editore, Bolonia, 1985, pág. 328. En el mismo sentido, GizzI, Elio: Manuale de Diritto regionale, Giuffrè editore, Milano, 1972, pág. 192.

(25) CAReTr, Paolo: "L'utilizzacione degli uffici degli enti locali», en Scriti in onore di Costantino Mortati, vol. II, Giuffrè editore, Varese, 1977, pág. 586.

(26) TERESI, F.: «La delegazione...», cit., pág. 364.

(27) Roversi MonaCo, F.: Commento allo statuto della Regione Emilia-Romagna, Giuffrè editore, Milano, 1972, pág. 180. 
Pero, volviendo a nuestro país, va a ser en el citado Informe de la Comisión de Expertos donde habremos de hallar las razones más inmediatas que motivaron la expresión de la mencionada técnica interadministrativa.

Parece que estas razones son, de un lado, el destacado papel que atribuyen a las Provincias en la configuración del «Estado de las Autonomías» y, por ende, a los órganos de gobierno y administración de las mismas, esto es, a las Diputaciones Provinciales (28). $\mathrm{Y}$, de otro lado, en la tendencia a evitar la burocratización de las Comunidades Autónomas: "... la formación de un aparato administrativo extenso - dice el Informe- debe evitarse tanto en los niveles centrales como en los periféricos» (29); y más adelante añade: «... por lo que respecta a la Administración periférica de la Comunidad Autónoma, su creación misma no debe llegar a producirse en ningún caso» (30). Y por esto ofertan la solución de que sean las Diputaciones quienes se encarguen de la gestión regional en el territorio de la Provincia.

Sin entrar en las razones de la oportunidad o no de esta solución, lo que sí debemos preguntarnos es acerca del régimen jurídico-administrativo aplicable a las Diputaciones Provinciales cuando gestionen los servicios periféricos propios de la Comunidad Autónoma. Dicho en otros términos, se trata de determinar si las relaciones entre ambos Entes van a tener carácter intersubjetivo o, por el contrario, carácter interorgánico.

A primera vista parece que, formalmente, nos encontramos en presencia de una relación intersubjetiva, en cuanto son dos Entes jurídico-públicos los que se relacionan. Sin embargo, pronto descubriremos que esto no es así, puesto que cuando las Diputaciones Provinciales realicen estas funciones no actúan como Entes públicos dotados de personalidad jurídica, sino como órganos de la Comunidad Autónoma. Es decir, en el cumplimiento de estas funciones no son los órganos de gobierno y administración de las Provincias, sino meros órganos periféricos de la Administración autonómica.

Así pues, en el ejercicio de estas funciones no existe descentrali-

(28) «Las Diputaciones deben quedar convertidas en el escalón administrativo intrarregional básico...», Informe..., cit., pág. 28.

(29) Ibídem, pág. 25.

(30) Ibidem, pág. 27. 
zación (que es una técnica de relación intersubjetiva) (31), sino desconcentración (que es una técnica de relación interorgánica, como ha señalado la totalidad de la doctrina) (32), impropia o especial o como se la quiera denominar, pero desconcentración al fin y al cabo.

En nuestro Ordenamiento jurídico ya existió una figura semejante, si bien nunca llegó a ponerse en práctica. La Ley 41/1975, de Bases del Estatuto del Régimen local, en su Base 48, dedicada a la «Colaboración de las Entidades locales a la realización de los servicios del Estado», punto 3, establecía lo siguiente:

«La desconcentración de funciones del Estado a órganos o Entidades de la Administración local solamente podrá hacerse por Ley, la que establecerá las previsiones necesarias para la transferencia de los correspondientes medios financieros en favor de las Entidades que asuman el cumplimiento de dichas funciones».

Este texto transcrito pasó luego a convertirse en el artículo 134 del Decreto 3046/1977, de 6 de octubre.

En esta norma se preveía, como vemos, que las Diputaciones Provinciales o Ayuntamientos - habla de Entidades locales- pudieran realizar funciones que el Estado les encomendara por Ley, convirtiéndose de esta suerte en órganos periféricos de la Administración del Estado.

El Informe de la Ponencia de esta Ley de Bases señala que el término desconcentración se utiliza porque lo que ocurre es que la Administración Central conserva su potestad, pero transfiere, con sus correspondientes medios financieros para poder ejercitarlas, funciones, desconcentrando y no descentralizando, ya que las funciones que lleva a cabo la Administración local son privativas de la Administración Central, la cual conserva íntegramente sus competencias (33).

En la discusión parlamentaria de estas Bases el profesor DE LA

(31) Sobre el tema de la descentralización nuestra doctrina ha sido bastante prolija. Vid., por todos, ARIÑo OrTIz, Gaspar: «Realidad y dogmática de la descentralización. Notas para la delimitación de un concepto», en Estudios en homenaje al Profesor Lopez Rod6, vol. I, Universidad de Santiago de Compostela-Universidad Complutense-Consejo Superior de Investigaciones Científicas, Madrid, 1972, págs. 171 y siguientes.

(32) La desconcentración ha sido una figura menos tratada por la doctrina. Sobre el tema vid. De la Vallina Velarde, Juan-Luis: "La desconcentración administrativa», Revista de Administración Pública, núm. 35, mayo-agosto 1961, págs. 75 y sigs.

(33) Tomo este argumento de la Ponencia de la intervención del señor Peralta España, vid. Diario de Sesiones de las Comisiones, núm. 591, de 24 de septiembre de 1975, pág. 24. 
Vallina (miembro de la Ponencia) justificó la utilización del término desconcentración y no el de delegación o descentralización, como sugerían otros miembros de la Comisión de Gobernación (34), aduciendo que «se quiere contemplar una modalidad de transferencia en que los Entes locales actúan no con personalidad jurídica, sino como órganos del Estado... y, por tanto, sometidos al Ordenamiento jurídico estatal y con todas las consecuencias de régimen económico y jurídico de los órganos del Estado» (35).

Pues bien: entendemos que esto mismo es predicable de la gestión ordinaria de los servicios periféricos propios de la Comunidad Autónoma a través de las Diputaciones Provinciales. Estas no actúan en cuanto Entidades locales, sino pura y simplemente como órganos de la Comunidad Autónoma. Los servicios objeto de articulación son los propios de la Comunidad Autónoma, esto es, siguen perteneciendo a la esfera de atribuciones de ésta, del mismo modo que las funciones desconcentradas en las Entidades locales seguían siendo privativas, como dice el Informe de la Ponencia, de la Administración Central. Es una fórmula de ejercicio por los Entes locales de competencias de las Comunidades Autónomas, quedándose en una mera colaboración burocrática, sin que se opere transferencia de competencia alguna.

Por tanto, opinamos que la relación que se da entre la Comunidad Autónoma y las Diputaciones Provinciales cuando éstas realizan la gestión ordinaria de los servicios propios de la Comunidad Autónoma es, sencillamente, de carácter interorgánico y no, como formalmente aparece, de carácter intersubjetivo, colocándose a la Entidad local (la Provincia, en este caso) en una situación de subordinación jerárquica respecto de la Comunidad Autónoma, situación que, cuando menos, es chocante con respecto a su carácter de Entidad local dotada de autonomía. Así se deduce, además, claramente, de lo dispuesto en el artículo 45, 1, del Estatuto de Autonomía de Andalucía cuando afirma que «todos los órganos encargados de la prestación de servicios o de la gestión, competencias y atribuciones de la Comunidad Autónoma dependen de ésta y se integran en su Administración».

(34) Así, el profesor MeILÁn Gil y el procurador señor Peralta España, Diario de Sesiones..., cit., págs. 23-25.

(35) Diario de Sesiones..., cit., pág. 25. 


\section{UN EJEMPLO: EL CASO ANDALUZ}

Esto que hemos señalado en el epígrafe anterior lo vemos claramente reflejado en una Comunidad Autónoma: la de Andalucía.

El artículo 4., 4 , del Estatuto de Autonomía andaluz, aprobado por Ley Orgánica 6/1981, de 30 de diciembre, establece lo siguiente:

«En los términos de una Ley del Parlamento andaluz y en el marco de la legislación del Estado, la Comunidad Autónoma articulará la gestión ordinaria de los servicios periféricos propios a través de las Diputaciones Provinciales...»(36).

Debemos hacer notar que en este texto legislativo se dice en términos imperativos «articulará», esto es, llega a ordenar que la gestión ordinaria de los servicios periféricos propios de la Comunidad Autónoma se articule a través de las Diputaciones Provinciales, hecho éste que nos resulta paradójico si tenemos en cuenta que al mismo tiempo que se obliga a la gestión ordinaria de los servicios propios de la Comunidad Autónoma a las Diputaciones Provinciales, se diga también que corresponde en exclusiva a la Comunidad Autónoma la organización de sus instituciones de autogobierno, siendo así que ya en el propio Estatuto de Autonomía, que es, recordemos, Ley Orgánica del Estado, se ha determinado, al menos en parte, dicha organización. No obstante, la doctrina de la Sentencia de 5 de agosto de 1983, como ha señalado el profesor Clavero (37), facilita la interpretación flexible de los Estatutos.

Pues bien: el mandato estatutario señalado en el artículo $4 .^{\circ}, 4$, es el que ha venido a cumplir la Ley 3/1983, de 1 de junio, de Organización Territorial de la Comunidad Autónoma de Andalucía (BOJA de 3 de junio), en sus artículos 21 a 24.

Del examen de estos preceptos podemos extraer las siguientes conclusiones:

En primer lugar, que no son todos los servicios de la Comunidad Autónoma los que se ejercerán a través de las Diputaciones Provinciales, sino solamente aquellos cuya naturaleza así lo permita, según señala el apartado $10^{\circ}$ del artículo 21 de esta Ley, lo que da lugar, a mi entender, a una gran indeterminación para conocer a priori cuáles puedan ser esos servicios que gestionarán las Dipu-

(36) Un comentario a este precepto puede verse en PÉREz Moreno, Alfonso, y otros: Comentarios al Estatuto de Andalucía, IGO, Sevilla, 1981, págs. 43 y sigs.

(37) Clavero Arévalo, M.: «La Provincia...», cit., pág. 2157. 
taciones y cuáles aquellos otros que su naturaleza no permite la. gestión por dichos órganos. Por otro lado, esto significa también que junto a las Diputaciones Provinciales actuando como órganos periféricos de la Comunidad Autónoma existirán otros órganos creados por ella misma para atender esos servicios que por su naturaleza no pueden ser gestionados por las Diputaciones Provinciales, con lo que la creación de la Administración periférica que se pretendía evitar con la utilización de este instrumento, como decía la Comisión de Expertos, no se logra; antes al contrario, se produce la duplicidad de órganos periféricos.

En segundo término, que la «asignación» de competencias se produce por acuerdo del Consejo de Gobierno de la Comunidad Autónoma, sin intervención alguna por parte de las Diputaciones Provinciales, que se limitan a aceptarla o rechazarla simplemente. Es decir, la asignación de estos servicios es prácticamente un acto unilateral de la Comunidad Autónoma que no tiene en excesiva consideración la voluntad de las Diputaciones Provinciales, lo que no. deja de ser incluso un menosprecio a la autonomía provincial. En Italia, por el contrario, la Región sólo puede recurrir a este instrumento previo acuerdo con los Entes locales, tal y como señalan, entre otros, los artículos 69 del Estatuto lombardo, 55 del veneciano, 57 del toscano, etc.

$\mathrm{Y}$, en tercer lugar, la Comunidad Autónoma se reserva sobre estas funciones unas facultades de dirección y control que son auténticamente poderes de jerarquía. Así, se reserva la potestad reglamentaria sobre la materia y, lo que es más, tratándose de funciones de ejecución, también sobre la organización del servicio; el establecimiento de recursos de alzada y la revisión de oficio de los. actos administrativos dictados por las Diputaciones Provinciales en el ejercicio de estas funciones; la designación de Director o Directores de Servicios -éstos son nombrados por el Pleno de la Diputación, pero a propuesta del Consejo de Gobierno de la Comunidad Autónoma (art. 21, 2)-; la fijación de módulos de funcionamiento. y financiación de niveles de rendimientos mínimos; la elaboración y el poder de dictar directrices sobre la gestión de las competencias; recabar, en cualquier momento, información sobre el ejercicio. de estas funciones; enviar comisionados, lo que nos parece excesivo a todas luces, habida cuenta de que ya la Comunidad Autónoma ha nombrado al Director del Servicio; formular los requerimientos pertinentes al Presidente de la Diputación para la subsana- 
UN EXPONENTE dE LA PROBLEMATICA ACTUAL ENTRE COMUNIDADES AUTONOMAS... 717

ción de las deficiencias observadas, y cualesquiera otras de análoga naturaleza a las anteriores.

En definitiva, como podemos ver, opinamos que la gestión ordinaria de los servicios periféricos propios de la Comunidad Autónoma a través de las Diputaciones Provinciales no responde ni mucho menos, como dice la Exposición de Motivos de la presente Ley, al principio de descentralización, al menos en este punto, sino todo lo más al principio de desconcentración, dándose lugar, por tanto, a una relación más bien de tipo jerárquico entre la Comunidad Autónoma y las Diputaciones Provinciales comprendidas en su ámbito territorial.

\section{REFLEXION CRITICA}

Indudablemente, resulta muy difícil prever el éxito futuro de la técnica que estamos analizando, aunque ya estamos en posesión de algunos datos que nos pueden servir para predecir ese futuro. Así, por ejemplo, la Comunidad Autónoma de Andalucía, a pesar de haber promulgado la Ley de Organización Territorial, que prevé la asignación de competencias que comporten la gestión ordinaria de los servicios periféricos a las Diputaciones Provinciales -como vimos en el epígrafe anterior-, no ha realizado, hasta el momento en que se escriben estas páginas, ninguna asignación de competencias en tal sentido; antes al contrario, han subsistido los órganos periféricos que con anterioridad había creado (38). El resto de las Comunidades Autónomas que han previsto esta técnica en sus Estatutos de Autonomía hasta el momento tampoco la han desarrollado (39).

En resumen, podemos decir con Enric Argullol Murgadas que «el esquema de administración indirecta previsto ha quedado como una simple declaración de intenciones, sin que haya trascendido a la realidad institucional» (40).

Quienes han defendido esta técnica de relación entre Comunidad

(38) El Decreto del Consejo de Gobierno de la Comunidad Autónoma de Andalucía, Decreto 17/1983, de 26 de enero, que prevé la existencia de Delegaciones de las Consejerías en cada Provincia, no ha sido ni derogado ni modificado.

(39) Recientemente en la Comunidad Autónoma de Castilla y León se ha aprobado la Ley 6/1986, de 6 de junio, Reguladora de las Relaciones entre la Comunidad de Castilla y León y las Entidades locales (B. O. C. y $L$. de 11 de junio), que no prevé en ninguno de sus artículos la mencionada técnica interadministrativa.

(40) Argullol Murgadas, Enric: "La Administración de las Comunidades Autónomas», REDC, núm. 15, septiembre-diciembre 1985, pág. 107. 
Autónoma y Diputaciones Provinciales han expuesto el argumento del ahorro del gasto público que se evitaría con esta medida, así como el de evitar el aumento de burocratización de la Administración autonómica. Pero aunque estos argumentos sean perfectamente válidos, deben ser matizados.

La creación de una nueva Entidad político-administrativa, cualquiera que sea, lleva necesariamente aparejada —casi biológicamente, diríamos- la creación de un aparato administrativo que se ocupe de las competencias que este nuevo Ente territorial va a asumir. Debemos afirmar que las Comunidades Autónomas no sólo pueden crear sus propias Administraciones, sino que, además, como ha escrito el profesor BAENA DEL ALCÁZAR (41), deben hacerlo necesariamente pese al perjuicio en contra de buena parte de la clase política. Las Comunidades Autónomas deben disponer de una organización capaz de ejercer eficazmente las competencias traspasadas y de prestar buenos y eficaces servicios al ciudadano, que es, al fin y al cabo, uno de los motivos que justifican su creación: acercar la Administración al administrado.

Por otro lado, debemos tener conciencia de que mucho de lo que se ha transferido a las Comunidades Autónomas ha sido, precisamente, los servicios periféricos de la Administración del Estado, por lo que las Comunidades Autónomas no van a crear ninguna Administración periférica, pues ésta ya se encuentra ahí, traspasada, transferida por el Estado. El escalón administrativo que se pretende no crear, al menos en gran parte, ya existe. Así, por ejemplo, cuando se ha transferido la materia de Sanidad a las Comunidades Autónomas, se las ha transferido los centros sanitarios, el personal sanitario, la organización administrativa, etc., es decir, no lo han tenido que crear: se lo han encontrado transferido; lo único que ocurre es que pasa a depender de la Comunidad Autónoma en lugar de depender del Gobierno central.

Además, las Diputaciones Provinciales, tal y como se encuentran hoy, no pueden atender, además de sus competencias como Ente local, las de gestión ordinaria de los servicios periféricos de la Comunidad Autónoma. Las Diputaciones Provinciales vendrían obligadas, de suceder esto, a tener una doble naturaleza: órgano de gobierno y administración de la Provincia en sus competencias propias y órgano periférico de la Comunidad Autónoma en las compe-

(41) Curso de Ciencia de la Administración, vol. I, Tecnos, Madrid, 1985, página 274. 
tencias asignadas, que incluso podrían ser las más, con lo que, a mi juicio, se estaría consiguiendo desvirtuar a la Provincia como Ente local y a la Diputación Provincial como órgano de gobierno y administración de ésta.

$\mathrm{Y}$ aún existen más razones, según pienso, para mostrar esta actitud crítica hacia la técnica objeto del presente análisis, razones que tienen un contenido jurídico-político. Desde este aspecto pueden producirse disfunciones, distorsiones, conflictos, en definitiva, entre ambos Entes. Porque ¿qué ocurriría si una o varias Diputaciones se mostrasen disconformes con la política marcada por los órganos de gobierno de la Comunidad Autónoma y se negasen a ejecutar las instrucciones dadas por éstos o, sin ir a tal extremo, retardasen la ejecución o ejecutaren esas instrucciones de distinto modo a como deseare la Comunidad Autónoma? La solución de revocar esas competencias asignadas significaría la inutilidad del sistema, la inutilidad de la técnica. Desde luego, nos parece difícil encontrar una buena solución. Los problemas que se podrían crear en las ya complejas relaciones Comunidad Autónoma-Diputaciones Provinciales serían imposibles de resolver.

Para conseguir los objetivos que se marcaron los autores del Informe al diseñar este instrumento de relación interadministrativa es preciso, pienso, utilizar otras técnicas.

Debe tenerse presente, como ha observado el profesor MEILÁN GIL (42), que la introducción del ámbito comunitario obliga a una redistribución de funciones correspondientes a los ámbitos provincial y municipal existentes. El carácter compuesto del Estado en la Constitución de 1978, según acertada expresión del Tribunal Constitucional (43), exige distribuir adecuadamente las competencias entre los distintos Entes territoriales que lo integran, dotados todos ellos de autonomía para la gestión de sus respectivos intereses.

Es decir, que siguiendo el principio de autonomía, vertebrador en buena parte de nuestro Texto constitucional, el Estado y las Comunidades Autónomas deben traspasar, prioritariamente como propias, a las Provincias aquellas competencias cuyo ejercicio sea más idóneo en el nivel provincial, «... de conformidad con los principios. de descentralización y de máxima proximidad de la gestión administrativa a los ciudadanos», como señala - in fine- el apartado $1 .^{\circ}$

(42) MeIlán Gil, J. L.: «Funcionalidad del territorio de las Comunidades Autónomas", RevisTa DE Estudios DE LA VIDA LOCAL, núm. 226, abril-junio 1985, pág. 295.

(43) Vid., entre otras, las Sentencias de 2 de febrero de 1981 y 28 de enero y 14 de junio de 1982. 
del artículo 2..$^{\circ}$ de la Ley $7 / 1985$, de 2 de abril, reguladora de las Bases del Régimen local. De igual modo que las Provincias deben transferir a las Comunidades Autónomas aquellas competencias que puedan ser mejor gestionadas a nivel regional, posibilidad ésta que no descarta la famosa Sentencia del Tribunal Constitucional sobre las Diputaciones catalanas de 28 de julio de 1981.

$\mathrm{Y}$ esta operación de redistribución de competencias puede y debe hacerse en cada una de las Leyes sectoriales básicas que dicten el Estado y las Comunidades Autónomas sobre cada una de las materias, tal y como viene señalado en los artículos $2 .^{\circ}, 2$, y 36,1 , de la Ley reguladora de las Bases del Régimen local. 


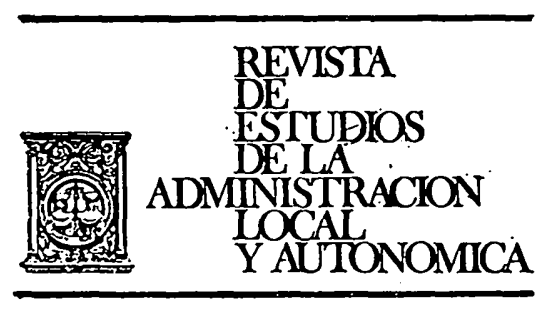

\section{CRONICAS}


REALA-1986, núm. 232. CALONGE VELAZQUEZ, ANTONIO. UN EXPONENTE DE LA PROBLEMATIC...

REALA-1986, núm. 232. CALONGE VELAZQUEZ, ANTONIO. UN EXPONENTE DE LA PROBLEMATIC... 